\title{
Treatment of Renal Anemia in Saudi Dialysis Patients: Between Darbepoetin Alfa and Recombinant Human Eryhthrpoietin (rHuEPO)
} Abdullah Khalaf Al-Hwiesh* and Ibrahiem Saeed Abdul-Rahman

Department of Internal Medicine and Nephrology Division, King Fahd University Hospital, Al Khobar, Dammam University, Dammam, Saudi Arabia

\begin{abstract}
Background: Darbepoetin alfa is an erythopoietic agent with a 3-fold longer elimination half-life than recombinant human erythropoietin (rHuEPO), which allows less frequent dosing, and hence it maintains an effective hemoglobin control at extended dose intervals compared with rHuEPO. This study assessed the efficacy and safety of unit doses of darbepoetin alfa for the treatment of renal anemia in hemodialysis (HD) and peritoneal dialysis (PD) patients.
\end{abstract}

Methods: In this prospective study, 143 dialysis patients (68 HD and 75 PD patients) maintained on stable rHuEpo treatment were switched to darbepoetin alfa at extended dose intervals by the same route of administration as previous rHuEpo therapy [intravenous (i.v.), $n=78$ or subcutaneous (s.c.), $n=65$ ]. Patients receiving rHuEpo two or three times a week were switched to darbepoetin alfa once a week and those receiving rHuEpo once a week were switched to darbepoetin alfa once every two weeks. The unit doses of darbepoetin alfa (10-150 ug) were titrated to maintain hemoglobin concentrations of 10-12 g/dl for 24 weeks.

Results: Hemoglobin $(\mathrm{Hgb})$ concentrations were maintained effectively in our patients regardless of the dose interval of darbepoetin alfa. The overall mean change in $\mathrm{Hgb}$ concentration from baseline to evaluation period was an increase of $0.18 \mathrm{~g} / \mathrm{dl}(95 \% \mathrm{Cl} \pm 0.16)$. Regardless of route of administration, darbepoetin alfa effectively maintained mean $\mathrm{Hgb}$ concentration above $11 \mathrm{~g} / \mathrm{dl}$ throughout the entire study period. Darbepoetin alfa administered by both the i.v. and s.c. routes resulted in stable mean $\mathrm{Hgb}$ concentrations during the evaluation period. Subjects with baseline $\mathrm{Hgb}$ concentrations $<11 \mathrm{~g} / \mathrm{dl}$ experienced significant mean increase in $\mathrm{Hgb}$ concentration from baseline to evaluation, which was more pronounced following i.v. than s.c. administration ( $0.79 \mathrm{vs} 0.55 \mathrm{~g} / \mathrm{dl}$ respectively). Relative to baseline, i.v. and s.c. darbepoetin alfa dosage requirements decreased in subjects with baseline $\mathrm{Hgb} \geq 11 \mathrm{~g} / \mathrm{dl}$ (21.64 to 15.86 $\mathrm{ug} /$ week and 21.95 to $18.52 \mathrm{ug} /$ week respectively $p=0.0214$ ), while there was a little increase in darbepoetin alfa dosage in subjects with baseline $\mathrm{Hgb}<11 \mathrm{~g} / \mathrm{dl}(25.22$ to $26.76 \mathrm{ug} / \mathrm{week}$ and 22.74 to $24.81 \mathrm{ug} / \mathrm{week}$ in the i.v. and s.c. groups respectively $p=0.0581$ ). The percentage change in dose requirements from baseline to evaluation period in all patients, regardless of route of administration was not significant $(2.28 \%, 95 \% \mathrm{Cl}-3.64,7.89)$. Hemoglobin concentrations were also effectively maintained in patients who received darbepoetin alfa once weekly and once every other week. Darbepoetin alfa was well tolerated in all HD and PD patients, and the safety profile was consistent with previous trials with darbepoetin alfa in dialysis patients.

Conclusion: The treatment of renal anemia in dialysis patients (both HD and PD) with unit doses of darbepoetin alfa is both effective and well tolerated. Moreover, administration of darbepoetin alfa by both i.v. and s.c. route is associated with stable Hgb concentration. Darbepoetin alfa administered i.v. or s.c once weekly or once every other week is an effective and safe treatment regimen for hemodialysis and peritoneal dialysis patients with renal anemia.

Keywords: ESRD; Dialysis; Anemia; Hemoglobin; Darbepoetin alfa; rHuEpo

\section{Introduction}

Erythropoiesis-stimulating agents have been credited with a reduced need for red cell transfusion and improved quality of life for patients with end- stage renal disease (ESRD) who have severe anemia [1]. Trials comparing lower and higher hemoglobin (Hgb) targets have been interpreted to suggest that targeting of a lower Hgb range would be a safer approach in these patients [2-4]. Darbepoetin alfa is a unique erythropoietic protein that by virtue of its longer elimination halflife [5] and greater in vivo biological activity [6] can be administered less frequently than rHuEpo. Several studies have confirmed that darbepoetin alfa can be administered less frequently than rHuEpo to correct and maintain Hgb in subjects with chronic kidney disease both on dialysis and not on dialysis [7-16]. Moreover it has been shown that, in contrast to rHuEpo, there is no difference in intravenous (i.v.) and subcutaneous (s.c.) dose requirements for darbepoetin alfa $[12,16]$. For the route of Erythropoiesis-stimulating agents, subcutaneous administration is more convenient than the i.v. administration in patients on peritoneal dialysis or those with chronic kidney disease without arterio-venous fistula [17]. The s.c. route improved the efficacy of therapy resulting in a reduced dosing requirements of Erythropoiesis-stimulating agents to maintain the target hemoglobin level [18]. However many patients on hemodialysis still continue to be treated via the i.v. route. The primary reason is probably the discomfort with s.c. injections. The s.c. administration of two or three times weekly causes pain at every injection. Once-weekly therapy using high dose of rHuEpo with an enlarged administration interval has been attempted since the 1990s, the results, however, were not encouraging [19]. Recent studies have demonstrated that darbepoetin alfa i.v. and s.c. dose

*Corresponding author: Dr. Abdullah K. Al-Hwiesh, King Fahd University Hospital, Al-Khobar, 31952, E-mail: dralhwiesh@yahoo.com

Received October 22, 2011; Accepted December 13, 2011; Published December 15, 2011

Citation: Al-Hwiesh AK, Abdul-Rahman IS (2011) Treatment of Renal Anemia in Saudi Dialysis Patients: Between Darbepoetin Alfa and Recombinant Human Eryhthrpoietin (rHuEPO). J Nephrol Therapeutic S10:001. doi:10.4172/2161-0959. S10-001

Copyright: (c) $2011 \mathrm{Al}-\mathrm{H} w i e s h \mathrm{AK}$, et al. This is an open-access article distributed under the terms of the Creative Commons Attribution License, which permits unrestricted use, distribution, and reproduction in any medium, provided the original author and source are credited. 
requirements are comparable $[11,20]$. The implication of this finding is clinically relevant, as it enables clinicians to base their decision on the most suitable route of administration of the erythropoietic-stimulating agents' therapy on clinical and not economic reasons. Moreover, it has been shown recently that i.v. darbepoetin after administered at extended dose intervals is as effective as i.v. rHuEpo in achieving and maintaining Hgb concentrations [9,12,21]. Our study was conducted in order to confirm further the efficacy and safety of unit doses of darbepoetin alfa given at extended dose intervals for maintaining $\mathrm{Hgb}$ concentrations within a defined target range in dialysis patients.

\section{Subjects and Methods}

\section{Subjects}

One-hundred and forty-three dialysis patients (68 on HD and 75 on $\mathrm{PD}$ ) were enrolled in this prospective study. Of the PD population, fortyeight (64\%) were on CAPD (continuous ambulatory peritoneal dialysis) and 27 (36\%) were on APD (automated peritoneal dialysis). Clinically stable subjects ( $>18$ years of age) with mean $\mathrm{Hgb}$ concentration between $10-12 \mathrm{~g} / \mathrm{dl}$, receiving HD or PD for at least 6 months were recruited. The study protocol required that patients were receiving a stable dose of rHuEpo, given once, twice or three times weekly (i.v. or s.c.) for at least 12 weeks prior to the study. To ensure adequate iron stores for supporting Erythropoiesis, entry criteria specified that transferrin saturation had to be $>20 \%$, or ferritin $>100 \mathrm{ug} / \mathrm{l}$. Patients with severe congestive heart failure (New York Heart Association class III or IV), uncontrolled hypertension (pre-dialysis diastolic blood pressure > $100 \mathrm{mmHg}$ ), recent or recurrent bleeding episodes, H.I.V., chronic inflammations ( 2 patients with bronchiectasis and 1 with pulmonary T.B.) or evidence of uncontrolled hyperparathyroidism were excluded from the study, as were those scheduled for a living-related kidney transplantation. Neither red blood cell transfusions nor major surgery were permitted within 12 weeks before the screening period. The study was conducted in accordance with the revised Declaration of Helsinki, and the study protocol was approved by our Institution's Research Ethics Committee and the patients were requested to give written informed consents before participation.

\section{Study drug}

The darbepoetin alfa (Aranesp TM, Amgen Inc., Thousand Oaks, California) used in the study is produced by recombinant DNA techniques and is expressed by cultured mammalian cells. Darbepoetin alfa was supplied in vials as a clear, colorless, sterile protein solution containing 20,50 , or $100 \mathrm{ug} / \mathrm{ml}$ protein.

\section{Study design}

This was a prospective, exploratory study to evaluate the efficacy and safety of switching stable dialysis patients from $\mathrm{rHuEpo}$ to darbepoetin alfa. After a 2-week screening and baseline period, subjects were switched from rHuEpo to darbepoetin alfa at an extended dose interval, using the same route of administration. Subjects who were receiving rHuEpo two or three times a week were switched to darbepoetin alfa once a week, and subjects who were receiving rHuEpo once a week were switched to darbepoetin alfa once every two weeks. A 200 IU rHuEpo: 1 ug darbepoetin alfa ratio was used to determine the starting dose when patients were switched from $\mathrm{rHuEpo}$ to darbepoetin alfa [22]. If a dose of rHuEpo did not equate exactly to a unit dose of darbepoetin alfa at switching, then the nearest available dose of darbepoetin alfa was used. Doses of darbepoetin alfa according to this equation ranged between 30-90 ug (Table 1). Subsequent darbepoetin alfa doses were titrated based on the $\mathrm{Hgb}$ response. The period after the first dose of darbepoetin alfa (weeks 1-20) was used for dose titration and maintenance of $\mathrm{Hgb}$, followed by a 4-week evaluation period (weeks 21-24) during which the primary efficacy end point was assessed. Due to the halflife of circulating red blood cells (about 60 days) in dialysis patients, it was anticipated that the equilibrium of $\mathrm{Hgb}$ concentrations after switching from rHuEpo to darbepoetin alfa would occur within 20-24 weeks [23]. Darbepoetin alfa dose was adjusted when two consecutive weekly Hgb values were outside the target range (10-12 g/dl). Dose adjustment was made by $+25-50 \%$ of the baseline dose. If serum ferritin levels were below $100 \mathrm{ug} / \mathrm{l}$ or transferring saturation $<20 \%$, i.v. iron was administered according to our intravenous iron protocol (Table 2) to maintain iron levels above this minimum. Adverse events and blood pressure were monitored throughout the study. Blood samples were drawn every 4 weeks for serum albumin, creatinine, blood urea nitrogen, calcium, phosphorus, AST, ALT and intact parathyroid hormone, ferritin levels and to screen for antibodies to erythropoietic proteins. A radio immune precipitation (RIP) screening assay was used to detect seroreactivity to darbepoetin alfa. In addition Residual kidney function (RKF) was assessed by measuring the Kt/V and estimating the patient's glomerular filtration rate (GFR) by calculating the mean of weekly creatinine clearance.

\section{Statistical analysis}

We compared the mean change in Hgb concentration between the baseline (mean of four values) and evaluation period (mean of

\begin{tabular}{|l|l|l|}
\hline Hgb level $(\mathbf{g} / \mathbf{d l})$ & rHuEpo dosage & Darbepoetin alfa dosage \\
\hline Hgb 10.5 or less & $6000 \mathrm{IU}, 3$ times/week & 90 ug, once/week \\
\hline Hgb $>10.5-<11.0$ & $6000 \mathrm{IU}, 2$ times/week & 60 ug, once/week \\
\hline Hgb $11-12.0$ & $6000 \mathrm{IU}$, once/week & 30 ug, once every 2 weeks \\
\hline Hgb $>12.0$ & Discontinued & Discontinued \\
\hline${ }^{*} \mathrm{Hgb}=$ hemoglobin & & \\
\hline
\end{tabular}

Table 1: Titration protocol of darbepoetin alfa according to $\mathrm{Hgb}^{*}$ concentrations

\begin{tabular}{|l|l|l|}
\hline Ferritin level $(\mathbf{n g} / \mathbf{d I})$ & Transferrin saturation $\%$ & I.V. iron dosage \\
\hline Ferritin $<100$ & & $100-200 \mathrm{mg} 2 \mathrm{X} /$ week \\
\hline $100<$ Ferritin $<200$ & $<20$ & $200 \mathrm{mg} 1 \mathrm{X} /$ week \\
\hline $200<$ Ferritin $<400$ & $<25$ & $200 \mathrm{mg} 1 \mathrm{X} / 2$ weeks \\
\hline $400<$ Ferritin $<600$ & $25-50$ & $200 \mathrm{mg} 1 \mathrm{X} / \mathrm{month}$ \\
\hline Ferritin $>600$ & $>50$ & Discontinued \\
\hline
\end{tabular}

Table 2: Intravenous iron protocol.

\begin{tabular}{|c|c|c|}
\hline Darbepoetin alfa $(=143)$ & & \\
\hline i.v. $(n=78)$ & s.c. $(n=65)$ & \\
\hline \multicolumn{3}{|l|}{ Sex, n (\%) } \\
\hline Male & $57(73.1)$ & $40(61.5)$ \\
\hline Female & 21. (26.9) & $25(38.5)$ \\
\hline Age (years) (Mean+SD) & $57.6 \pm 13.6$ & $59.2 \pm 14.5$ \\
\hline Weight $(\mathrm{Kg})($ Mean $\pm \mathrm{SD})$ & $71.4 \pm 12.4$ & $73.1 \pm 13.8$ \\
\hline D.M., n (\%) & $33(42.3)$ & $30(46.2)$ \\
\hline H.P.N., n (\%) & $60(76.9)$ & $51(78.5)$ \\
\hline CRP (mg/L) (Mean \pm SD) & $2.8 \pm 1.3$ & $2.7 \pm 1.7$ \\
\hline \multicolumn{3}{|l|}{ Dialysis modality } \\
\hline HD, n (\%) & $38(48.7)$ & $30(46.2)$ \\
\hline PD, n (\%) & $40(51.3)$ & $35(53.8)$ \\
\hline \multicolumn{3}{|l|}{ Frequency of darbepoetin alfa } \\
\hline Once per week, n (\%) & $14(17.9)$ & $16(24.6)$ \\
\hline Once every 2 weeks, n (\%) & $64(82.1)$ & $49(75.4)$ \\
\hline
\end{tabular}

D.M= diabetes mellitus, H.P.N. = hypertension, $\mathrm{CRP}=\mathrm{C}$-Reactive protein, $\mathrm{HD}=$ hemodialysis, $\mathrm{PD}=$ peritoneal dialysis

Table 3: Patients' characteristics. 
four values). Based on a previous darbepoetin alfa study [11], where a $\mathrm{SD}$ of $0.8 \mathrm{~g} / \mathrm{dl}$ was observed for change in $\mathrm{Hgb}$, it was estimated that detection of a change in Hgb concentration of $0.7 \mathrm{~g} / \mathrm{dl}$ or more between baseline and the evaluation period (weeks 21-24) is significant. The number and percentage of evaluable patients who successfully maintained $\mathrm{Hgb}$ concentration (mean $\mathrm{Hgb}$ concentration $>10.0 \mathrm{~g} / \mathrm{dl}$ during the evaluation period and the exact $95 \%$ confidence intervals (CIs) are presented. The mean change in $\mathrm{Hgb}$ (95\% CI) from baseline to evaluation period for patients who successfully maintained Hgb is presented, along with the median change (95\% CI) in average dose of darbepoetin alfa. Summary statistics (mean or geometric mean, median, SD and range for continuous variables, and number and percentage of subjects in each category (for categorical variable) are presented for baseline, efficacy and safety. Change in $\mathrm{Hgb}$ and dose is summarized with means (geometric means for dose) and 95\% CI. All statistical analyses were performed with the SAS System Version 8.2.

\section{Results}

A total of 143 subjects were enrolled in the study. Subjects' baseline characteristics were similar regardless of the route of administration of darbepoetin alfa, and were representative of dialysis population (Table 3). Seventy-five (52.4\%) patients were on PD and 68 (47.6\%) were on HD. Seventy-eight (54.5\%) subjects received darbepoetin alfa I.V. and $65(45.5 \%)$ subjects received s.c. darbepoetin alfa. Forty-one (out of 78, $52.6 \%$ ) of the I.V. group were on PD and 37 (out of 78, 47.4\%) were on HD. Of the 65 s.c. group, 34 (out of $65,52.3 \%$ ) patients were on $\mathrm{PD}$ and 31 (out of $65,47.7 \%$ ) patients were on HD. The mean age was similar in both groups (57.6 vs 59.2). The most common cause of ESRD was diabetes mellitus in both the i.v. and s.c. groups ( $42.3 \%$ and $46.2 \%$ $\mathrm{p}>0.05)$. Baseline serum albumin and other biochemical parameters were similar to those during the evaluation period (Table 3). Parameters of dialysis adequacy such as $\mathrm{Kt} / \mathrm{V}(1.9$ vs. $1.8, \mathrm{p}=0.715)$ and weekly creatinine clearance $(66.3 \pm 5.8$ vs. $65.6 \pm 4.5 \mathrm{~L} /$ week/1.732, $\mathrm{p}=0.313)$, before and after darbepoetin alfa use were also similar (Table 4$)$. The mean $\mathrm{Hgb}$ concentration at baseline was $11.21 \mathrm{~g} / \mathrm{dl}$ (range 10.5-12.0 $\mathrm{g} / \mathrm{dl})$. A total of 98 (68.5\%) subjects had a baseline $\mathrm{Hgb}$ concentration $>11 \mathrm{~g} / \mathrm{dl}$. All subjects completed both the 20-week dose titration period and the subsequent 4 -week evaluation period. The overall mean change in $\mathrm{Hgb}$ concentration from baseline to evaluation period was an increase of $0.18 \mathrm{~g} / \mathrm{dl}(95 \% \mathrm{CI}+0.16)$ (Table 5). Regardless of route of administration, darbepoetin alfa effectively maintained mean $\mathrm{Hgb}$ concentration above $11 \mathrm{~g} / \mathrm{dl}$ throughout the entire study period (Figure

\begin{tabular}{|l|l|l|l|}
\hline Before & After & $\boldsymbol{p}$ value & \\
\hline Kt/N & 1.9 & 1.8 & 0.715 \\
\hline WCrCl (L/week/1.732) & $66.3 \pm 5.8$ & $65.6 \pm 4.5$ & 0.313 \\
\hline BUN (mg/dl) & $75.7 \pm 16.3$ & $74.4 \pm 18.2$ & 0.112 \\
\hline Creatinine (mg/dl) & $10.8 \pm 3.3$ & $11.2 \pm 3.8$ & 0.074 \\
\hline Calcium (mg/dl) & $8.3 \pm 1.1$ & $8.6 \pm 0.6$ & 0.279 \\
\hline Phosphorus (mg/dl) & $5.5 \pm 1.3$ & $5.6 \pm 1.2$ & 0.224 \\
\hline Albumin (g/dl) & $3.9 \pm 1.2$ & $4.1 \pm 0.3$ & 0.266 \\
\hline AST (U/L) & $21.8 \pm 11.2$ & $21.5 \pm 11.5$ & 0.823 \\
\hline ALT (U/L) & $22.2 \pm 12.0$ & $20.8 \pm 13.4$ & 0.409 \\
\hline iPTH (pg/ml) & $172.4 \pm 68.9$ & $169.8 \pm 62.3$ & 0.118 \\
\hline
\end{tabular}

$\mathrm{WCrCl}=$ weekly creatinine clearance, $\mathrm{AST}=$ aspartate aminotransferase, $\mathrm{ALT}=$ alanine aminotransferase, iPTH = intact parathyroid hormone

Table 4: Differences in Kt/ $\mathrm{V}$, weekly creatinine clearance and serum biochemical parameters before and after use of darbepoetin alfa.

\begin{tabular}{|l|l|l|}
\hline $\begin{array}{l}\text { Route of administration } \\
\text { concentration }\end{array}$ & Mean baseline $\mathbf{H g b}$ & Mean change in Hgb \\
\hline l.v. $(\mathbf{n}=\mathbf{7 8})$ & & \\
\hline $\mathrm{Hgb}<11 \mathrm{~g} / \mathrm{dl}(\mathrm{n}=22)$ & $10.56(10.52$ to 10.61$)$ & $0.79(0.64$ to 0.95$)$ \\
\hline $\mathrm{Hgb} \geq 11 \mathrm{~g} / \mathrm{dl}(\mathrm{n}=56)$ & $11.83(11.78$ to 11.87$)$ & $-0.05(-0.15$ to 0.04$)$ \\
\hline S.c. $(\mathbf{n}=65)$ & & \\
\hline $\mathrm{Hgb}<11 \mathrm{~g} / \mathrm{dl}(\mathrm{n}=20)$ & $10.54(10.49$ to 10.61$)$ & $0.55(0.38$ to 0.67$)$ \\
\hline $\mathrm{Hgb} \geq 11 \mathrm{~g} / \mathrm{dl}(\mathrm{n}=45)$ & $11.86(11.82$ to 11.92$)$ & $-0.18(-0.33$ to 0.14$)$ \\
\hline
\end{tabular}

Table 5: Mean $(95 \% \mathrm{Cl})$ change in $\mathrm{Hgb}^{*}$ from baseline to evaluation (weeks 21 24).

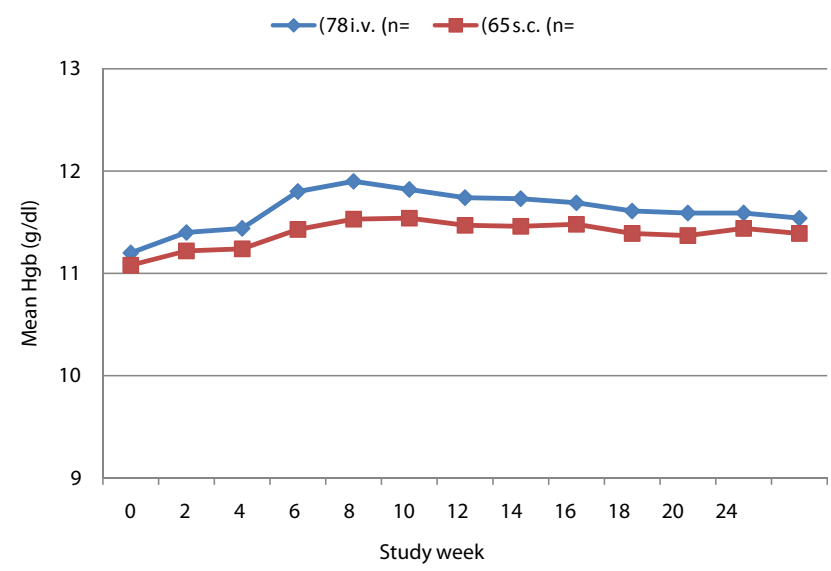

Figure 1: Mean hemoglobin concentrations $(95 \% \mathrm{Cl})$ over time by route of administration.

1). Mean Hgb concentration increased most markedly over the first 10 weeks of darbepoetin alfa treatment (Figure 1). Darbepoetin alfa administered by both the i.v. and s.c. routes resulted in stable mean $\mathrm{Hgb}$ concentrations during the evaluation period (Figure 2). Subjects with a baseline $\mathrm{Hgb}$ concentration $<11 \mathrm{~g} / \mathrm{dl}(\mathrm{n}=42)$ experienced a clinically significant mean increase in Hgb concentration of $0.62 \mathrm{~g} /$ dl $(95 \%$ CI $0.52+0.71)$ at evaluation. Subjects with a baseline $\mathrm{Hgb}$ concentration $>11 \mathrm{~g} / \mathrm{dl}(\mathrm{n}=101)$ experienced a mean decrease of $0.11 \mathrm{~g} /$ dl (95\% CI -0.17 to -0.06$)$. Subjects with baseline Hgb concentrations $<11 \mathrm{~g} / \mathrm{dl}$ experienced significant mean increase in Hgb concentration from baseline to evaluation, which was more pronounced following i.v. than s.c. administration ( 0.79 vs. $0.55 \mathrm{~g} / \mathrm{dl}$ respectively) (Table 5). Investigation of the mean weekly darbepoetin alfa requirements by route of administration during the evaluation period revealed that relative to baseline, i.v. and s.c. dosage requirements decreased in subjects with baseline $\mathrm{Hgb}>11 \mathrm{~g} / \mathrm{dl}$ (21.64 to $15.86 \mathrm{ug} /$ week and 21.95 to $18.52 \mathrm{ug} /$ week respectively $\mathrm{p}=0.0214$ ), while there was a little increase in darbepoetin alfa dosage in subjects with baseline $\mathrm{Hgb}$ $<11 \mathrm{~g} / \mathrm{dl}$ (25.22 to $26.76 \mathrm{ug} /$ week and 22.74 to $24.81 \mathrm{ug} /$ week in the i.v. and s.c. groups respectively $\mathrm{p}=0.0581$ ) (Table 6). However, at a time when steady state is expected to be reached, the mean dose of study drug was not different in both the i.v. and s.c. treatment groups (Figure 3). The ratio (95\% CI) of i.v. to s.c. darbepoetin alfa was 1.11 at baseline, reflecting the higher i.v. rHuEpo dose requirements at time that patient switched to darbepoetin alfa. At evaluation, the ratio was 0.97 , indicating that overall, the administered dose by the i.v. and s.c. routes were not different. The percentage change in dose requirements from baseline to evaluation period in all patients, regardless of route of administration was not significant $(2.28 \%, 95 \%$ CI -3.64, 7.89). 


\section{Safety}

Out of the 143 study subjects, $12(8.4 \%)$ patients experienced at least one adverse event that was considered by the investigator to be treatment related. these included injection site pain, diarrhea and hypertension. Analyses of the adverse event profile by age, sex, dialysis modality and administration route revealed no notable differences in the incidence rates for any of these subgroups. There were no cases of antibody-mediated pure red cell aplasia associated with darbepoetin alfa treatment. Over the study period, no relevant changes were observed in the mean systolic and diastolic blood pressure values, and there was no clinically relevant change in the use of anti-hypertensive medications. There were no changes in laboratory or biochemical variables associated with darbepoetin alfa treatment. Mean serum ferritin concentration was $532.5 \mathrm{ug} / \mathrm{l}$ at baseline and 541.7 at evaluation. In addition the mean

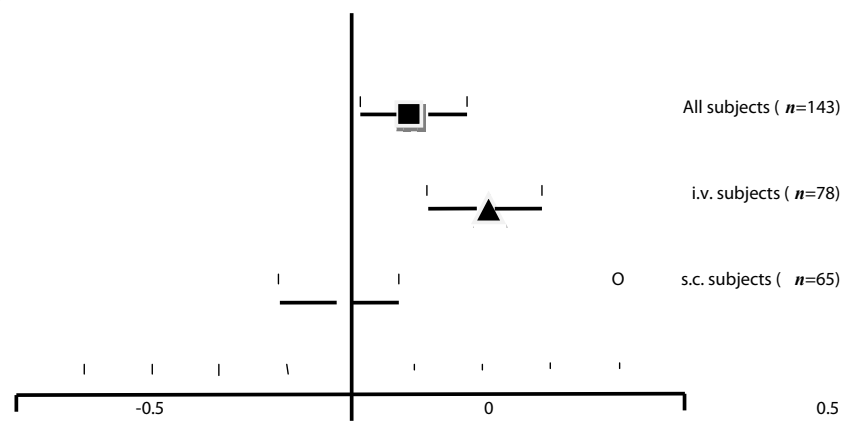

Figure 2: Mean change $(95 \% \mathrm{Cl})$ in $\mathrm{Hgb}$ concentration between baseline and the evaluation period by route of administration.

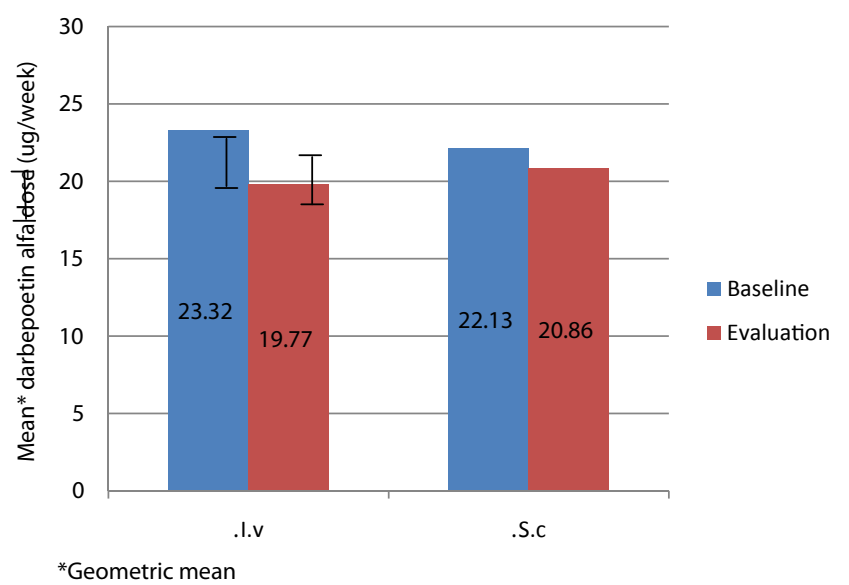

Figure 3: Mean $(95 \% \mathrm{Cl})$ weekly dose of darbepoetin alfa by route of administration.

\begin{tabular}{|l|l|l|}
\hline Route of administration & Baseline (ug/week)* & Evaluation (ug/week) \\
\hline I.v. & & \\
\hline $\mathrm{Hgb}<11 \mathrm{~g} / \mathrm{dl}(\mathrm{n}=22)$ & $25.22(23.19 \pm 27.34)$ & $26.76(25.87 \pm 28.25)$ \\
\hline $\mathrm{Hgb} \geq 11 \mathrm{~g} / \mathrm{dl}(\mathrm{n}=56)$ & $21.64(20.24 \pm 25.11)$ & $15.86(14.68 \pm 16.18)$ \\
\hline S.c. & & \\
\hline $\mathrm{Hgb}<11 \mathrm{~g} / \mathrm{dl}(\mathrm{n}=20)$ & $22.74(21.31 \pm 24.56)$ & $24.81(22.69 \pm 27.41)$ \\
\hline $\mathrm{Hgb} \geq 11 \mathrm{~g} / \mathrm{dl}(\mathrm{n}=45)$ & $21.95(20.44 \pm 22.76)$ & $18.52(16.93 \pm 19.12)$ \\
\hline
\end{tabular}

\section{*Geometric mean}

Table 6: Mean $(95 \% \mathrm{Cl})$ weekly darbepoetin alfa dose requirements at baseline an evaluation (weeks 21-24). transferring saturation remained above $20 \%$ throughout the study (29.8\% at baseline and $27.7 \%$ at evaluation).

\section{Discussion}

Previous studies have shown that darbepoetin alfa can effectively maintain the Hgb concentration when given at extended dose intervals relative to $\mathrm{rHuEpo}$ in dialysis patients [9-13]. The results of our study further confirm the results of these earlier trials and indicate that unit dosing with darbepoetin alfa can effectively and safely maintain $\mathrm{Hgb}$ concentration within a target range after switching from rHuEpo at extended dose intervals. Mean Hgb concentrations were maintained above $11 \mathrm{~g} / \mathrm{dl}$ throughout the evaluation period, regardless of route and frequency of administration. We noticed that i.v. darbepoetin alfa administration was associated with a higher increase in $\mathrm{Hgb}$ concentration compared with s.c. darbepoetin alfa. Following i.v. administration, there was an increase of $\mathrm{Hgb}$ of $0.78 \mathrm{~g} / \mathrm{dl}$ relative to baseline, which was moreover associated with a decrease of i.v. weekly dose requirements of over $20 \%$. While overall s.c. weekly dose requirements increase over the study period, this appears to be due to the fact that patients with baseline Hgb concentrations $<11 \mathrm{~g} / \mathrm{dl}$ were sub optimally controlled while being treated with rHuEpo. The dose of s.c. darbepoetin alfa was subsequently increased in these patients over the course of the study, and this was associated with a Hgb increase of almost $0.6 \mathrm{~g} / \mathrm{dl}$. Moreover, regardless of $\mathrm{Hgb}$ category at baseline (< 11.0 or $>11.0 \mathrm{~g} / \mathrm{dl}$ ), following i.v. administration, there was an increase in Hgb concentration that was associated with a decrease in weekly requirements of darbepoetin alfa. The observation that i.v. and s.c. darbepoetin alfa dose requirements were not significantly different at evaluation, results mainly from the decrease in i.v. dose requirements during the course of the study. This contrasts markedly with the previous decade of experience with rHuEpo. Despite reducing the frequency of administration of darbepoetin alfa, there was no change in mean $\mathrm{Hgb}$ concentration from baseline to the evaluation period in the overall study population. Indeed, mean Hgb concentrations were maintained above the European Best Practice Guidelines recommendation of 11.0 $\mathrm{g} / \mathrm{dl}$ throughout the entire study period [24]. The Hgb concentrations increased over the initial 10-week period of the study, which was accompanied by a stabilization period over weeks $10-24$. The slight decline in $\mathrm{Hgb}$ concentrations after the week 10 is probably reflective of subjects achieving the target $\mathrm{Hgb}$ concentration of $>11.0 \mathrm{~g} / \mathrm{dl}$ and therefore required by the study protocol to have a dose reduction (data not shown). Of these subjects who met the threshold of $>11.0 \mathrm{~g} / \mathrm{dl}, 62 \%$ did so during weeks 1-10 and the remaining 38\% met the threshold during weeks $10-24$. Approximately $31.5 \%$ of patients ( $45 / 143$ subjects) had a baseline $\mathrm{Hgb}$ concentration $<11.0 \mathrm{~g} / \mathrm{dl}$ suggesting that they were sub optimally treated with rHuEpo. In keeping with the observations of a previous study [12], these patients experienced a significant mean increase in $\mathrm{Hgb}$ of almost $0.7 \mathrm{~g} / \mathrm{dl}$ after switching to darbepoetin alfa. The increase in this study population was even more pronounced in the subgroup receiving i.v. darbepoetin alfa $(+0.79 \mathrm{~g} / \mathrm{dl})$, although there was also clinically significant $(+0.55 \mathrm{~g} / \mathrm{dl})$ increase in patients who received s.c. darbepoetin alfa. These data suggest that patients will be able to maintain target $\mathrm{Hgb}$ concentrations recommended for European patients with renal anemia [24] when switched from rHuEpo to darbepoetin alfa at extended dose intervals. Current treatment guidelines recommend that, given its pharmacokinetic profile, rHuEpo should be administered two or three times weekly for the treatment of anemia in dialysis patients [24,25]. Although $\mathrm{rHuEpo}$ 
has been evaluated using a once weekly schedule for maintaining Hgb concentrations [26,27], this was undertaken in a limited number of stable and highly selected HD patients. In addition, our study showed that there was no significant difference between i.v. and s.c. darbepoetin alfa administration in maintaining Hgb concentrations to the target level, in contrast with rHuEpo where dose requirements for i.v. dosing were approximately one-third higher than for s.c. dosing $[9,11,14]$. The effectiveness and safety profile in patients receiving darbepoetin alfa once every two weeks was very similar to that observed in patients on the once-weekly regimen and both regimens were consistent with results reported previously $[9,11,28]$. In addition, the similar levels of $\mathrm{Kt} / \mathrm{V}$, weekly creatinine clearance, serum albumin and other biochemical parameters indicate the stable condition of our patients throughout the study period. Furthermore, the ability to dose patients less frequently with darbepoetin alfa may have economic implications for healthcare providers, especially in relation to reduced nursing time, and notwithstanding the improved convenience for the patients. It is anticipated that future studies will address these issues.

\section{Conclusion}

This study indicates that renal anemia treatment with unit doses of darbepoetin alfa in dialysis patients can effectively and safely maintain hemoglobin concentrations with either once weekly or once every other week administration. In common with a previous darbepoetin alfa trial in dialysis patients, i.v. and s.c. dose requirements were not different. Clinically, i.v. darbepoetin alfa may provide improved outcomes over i.v. rHuEpo, at a reduced frequency of administration, and with the advantages of sparing patients the discomfort of repetitive s.c. injections. The results of this study suggest that the use of darbepoetin alfa in dialysis patients can optimize anemia management for patients with ESRD and for healthcare providers.

\section{Acknowledgment}

The authors express their deep thanks and appreciation for all the hemodialysis and peritoneal dialysis staff and technicians at King Fahd University Hospital, Dammam University.

\section{References}

1. Eschbach JW, Abdulhadi MH, Browne JK, Delano BG, Downing MR, et al (1998) Recombinant human erythropoietin in anemic patients with end-stage renal disease: results of a phase III multicenter clinical trial. Ann Intern Med 111: $992-1000$.

2. Singh AK, Szczech L, Tang KL, Barnhart H, Sapp S, et al. (2006) Correction of anemia with epoetin alfa in chronic kidney disease. N Engl J Med 355: 20852098.

3. Besarab A, Bolton WK, Browne JK, Egrie JC, Nissenson AR, et al. (1998) The effect of normal as compared with low hematocrit values in patients with cardiac disease who are receiving hemodialysis and epoetin. $\mathrm{N}$ Engl J Med 339: 584-590.

4. Szczech LA, Barnhart HX, Sapp S, Felker GM, Hernandez A, et al. (2010) A secondary analysis of the CHOIR trial shows that comorbid conditions differentially affect outcomes during anemia treatment. Kidney Int 77: 239-246.

5. Macdougall IC, Gray SJ, Elston O, Breen C, Jenkins B, et al. (1999) Pharmacokinetics of novel erythropoiesis stimulating protein compared with epoetin alfa in dialysis patients. J Am Soc Nephrol 10: 2392-2395.

6. Egrie JC, Browne JK (2001) Development and characterization of novel erythropoiesis stimulating protein (ESP). Nephrol Dial Transplant 16: 3-13.

7. Coyne D, Ling BN, Toto R, McDermott-Vitak AD, Trotman ML, et al. (2000) Novel erythropoiesis stimulating protein (NESP) corrects anemia in dialysis patients when administered at reduced dose frequency compared with recombinant human erythropoietin (rHuEpo). J Am Soc Nephrol 11: A1380.

8. Graf H, Lacombe JL, Braun J, Gomes da Costa AA (2000) Novel Erythropoiesis stimulating protein (NESP) effectively maintains Hemoglobin $(\mathrm{Hgb})$ when administered at a reduced dose frequency compared with recombinant human erythropoietin (r-RHuEpo) in end-stage renal disease patients. J Am Soc Nephrol 11: A1317.

9. 9. Nissenson AR, Swan SK, Lindberg JS, Soroka SD, Beatey RN, et al. (2002) Randomized controlled trial of darbepoetin alfa for the treatment of anemia in hemodialysis patients. Am J Kidney Dis 40: 110-118.

10. Vanrenterghem $Y$, Jadoul M, Foret M, Walker R (2001) Novel erythropoiesis stimulating protein (NESP) administered once every 3 weeks by the intravenous or subcutaneous route maintains hemoglobin $(\mathrm{Hb})$ in dialysis patients. J Am Soc Nephrol 365: A1878

11. Vanrenterghem Y, Barany P, Mann JEF, Kerr PG, Wilson J, et al. (2002) Randomized trial of darbepoetin alfa for treatment of renal anemia at a reduced dosing frequency compared with rHuEpo in dialysis patients. Kidney Int 62 2167-2175.

12. Locatelli F, Canaud B, Giacardi F, Martin-Malo A, Baker N, et al. (2003) Treatment of anemia in dialysis patients with unit dosing of darbepoetin alfa at a reduced frequency relative to recombinant human erythropoietin (rHuEpo) Nephrol Dial Transplant 18: 362-369.

13. Braun J (2002) Darbepoetin alfa administered once every 4 weeks maintains $\mathrm{Hb}$ levels in patients with chronic kidney disease (CKD) receiving dialysis. [abstract M317]. Nephrol Dial Transplant $17: 136$.

14. Locatelli F, Olivares J, Walker R, Wilkie M, Jenkins B, et al. (2001) Nove erythropoiesis stimulating protein for treatment of anemia in chronic renal insufficiency. Kidney Int 60: 741-747.

15. Suranyi MG, Lindberg JS, Navarro J, Elias J, Brenner RM, et al. (2003) Treatment of anemia with darbepoetin alfa administered de novo once every other week in chronic kidney disease. Am J Nephrol 23: 106-111.

16. Walczyk M, Agarwal A Ling B (2003) Aranesp ${ }^{\mathrm{TM}}$ (darbepoetin alfa) administered once monthly maintains hemoglobin levels in patients with chronic kidney disease (CKD). National Kidney Foundation Clinical Nephrology Meeting, Spring 2003. Dallas

17. Lee YK, Kim SG, Seo JW, Oh JE, Yoon JW, et al. (2008) A comparison between once-weekly and twice- or thrice-weekly subcutaneous injection of epoetin alfa: results from a randomized controlled multicenter study. Nephro Dial Transplant 23: 3240-3246

18. Besrab A, Reyes CM, Hornberger J (2002) Meta-analysis of subcutaneous versus intravenous epoetin in maintenance treatment of anemia in hemodialysis patients. Am J Kidney Dis 40: 439-446.

19. Macdougall IC (2002) Once weekly erythropoietic therapy: is there a difference between the available preparations?. Nephrol Dial Transplant 17: 2047-2051.

20. Canaud B (2002) Darbepoetin alfa dose requirements for i.v. and s.c. administration are equivalent in anemic dialysis patients [Abstract M319] Nephrol Dial Transplant 17: 137.

21. Horl WH (2002) IV darbepoetin alfa is more effective than IV rHu Epo in maintaining target $\mathrm{Hb}$ concentrations in patients with renal anemia [abstract O77]. Nephrol Dial Transplant 17: 24

22. Aljama P, Bommer J, Canaud B, Carrera F, Eckardt KU, et al. (2001) Practica guidelines for the use of NESP in treating renal anemia. Nephrol Dial Transplant 16: 22-28.

23. Uehlinger DE, Gotch FA, Sheiner LB (1992) A pharmacodynamic model of erythropoietin therapy for uremic anemia. Clin Pharmacol Ther 51: 76-89.

24. Cameron JS (1999) European Best Practice Guidelines for the management of anemia in patients with chronic renal failure. Nephrol Dial Transplant 14: 1-50.

25. (1997) NKF-DOQI clinical practice guidelines for the treatment of anemia of chronic renal failure. National Kidney Foundation Dialysis Outcomes Quality Initiative. Am J Kidney Dis 30: 192-240.

26. Weiss LG, Clyne N, Divino Fihlho J, Frisenette-Fich C, Kurkus J, et al (2000) The efficacy of once weekly compared with two or three times-weekly subcutaneous epoetin beta: results from a randomized controlled multicenter trial. Swedish Study Group. Nephrol Dial Transplant 15: 2014-2019.

27. Locatelli F, Baldamus CA, Villa G, Ganea A, Martin de Francisco AL (2002) On behalf of the Study Group. Once-weekly compared with three-times weekly subcutaneous epoetin beta: results from a randomized multicenter, therapeuticequivalence study. Am J Kidney Dis 40: 119-125

28. Nissenson AR (2001) Novel erythropoiesis stimulating protein for managing the anemia of chronic kidney disease. Am J Kidney Dis 38: 1390-1397. 